\title{
Circuitos migratorios, estrategias y flexibilidad laboral en la huasteca poblana
}

\author{
Antonio Fuentes Díaz
}

\section{María Eugenia D’Aubeterre y María Leticia}

RiverMAR PÉREZ (EDS.), 2011

Migraciones en la huasteca poblana.

Actores y procesos

Instituto de Ciencias Sociales y Humanidades, Benemérita

Universidad Autónoma de Puebla, 174 pp.

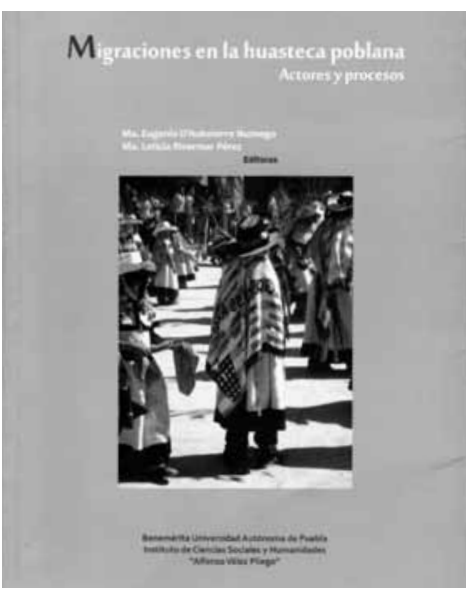

$M$

Tigraciones en la huasteca poblana. Actores y procesos, editado por María Eugenia D’Aubeterre y Leticia Rivermar, estudia las transformaciones en los circuitos migratorios en la zona conocida como la Huasteca durante los últimos 30 años en el área perteneciente a la Sierra Norte de Puebla y registra los cambios en las estrategias de reproducción social de los habitantes de dichas comunidades a partir de la migración interna e internacional de la región. El libro, producto del trabajo de tres años, centrado en el municipio de Pahuatlán y sintetizado en 174 páginas, está formado por seis capítulos y cuenta con la participación de estudiantes de maestría y doctorado.

\section{EJE DEL LIBRO}

Migratory Circuits, Strategies and Flexible Labor in the Huasteca Poblana

Antonio Fuentes Díaz: Instituto de Ciencias Sociales y Humanidades, Benemérita Universidad Autónoma de Puebla, Puebla, México anfudi@gmail.com

Desacatos, núm. 44, enero-abril 2014, pp. 216-218
El eje que vertebra los seis artículos es explorar un nuevo circuito migratorio, constituido por la migración internacional rural-urbana, del municipio de 
Pahuatlán y sus juntas auxiliares hacia la ciudad de Durham, Carolina del Norte, en los últimos años. Los capítulos permiten al lector profundizar en aspectos específicos de este circuito. Esta aproximación resalta tanto las transformaciones macroestructurales que lo detonaron como los aspectos locales y nacionales que han contribuido a configurarlo. Se establecen y se entrecruzan antiguos y nuevos ejes de desigualdad: étnica, de género y edad, bajo una experimentación de la clase en nuevos contextos. Se utilizaron técnicas cuantitativas y cualitativas en la investigación, de esta manera fue posible cruzar información estadística con el trabajo etnográfico y describir las particularidades de las estrategias de migración de cada localidad del municipio, y la vinculación con otras esferas, como la educativa y las políticas sociales. Destaca la propuesta metodológica de enfocar los corredores formados en las dinámicas migratorias, en lugar de adoptar la comunidad como área de análisis, lo que permite, de acuerdo con las autoras, pormenorizar las interacciones en áreas que trascienden los límites territoriales administrativos y el protagonismo de actores diversos, desde las agencias del Estado hasta el coyotaje.

\section{CIRCUITO MIGRATORIO Y ACUMULACIÓN}

Dicha exploración se orienta de manera pertinente desde la perspectiva del trabajo, en el entendido de que los migrantes se insertan en mercados laborales globales en condiciones que utilizan su flexibilidad como momento de rentabilidad en el proceso de acumulación de capital. La migración en la región se basaba en desplazamientos internos, hacia la capital del país o al estado de Hidalgo, como lo documenta el estudio de Leticia Rivermar y Diana Villegas. Sin embargo, la migración internacional emerge como un proceso conspicuo hacia mediados de la década de 1990. En ese sentido, la explicación presenta estos incrementos producidos por las transformaciones globales en el proceso de acumulación, signados por la progresiva pérdida de sustentabilidad de la agricultura y el consecuente crecimiento de los sectores secundario y terciario. Ilustran lo anterior el declive del cultivo de la caña y la fabricación del piloncillo como actividades económicas principales hacia fines de los años sesenta del siglo pasado, el descenso de la cafeticultura ante la abrupta caída en los precios del café durante la primera mitad de la década de 1990 y la desvinculación de las agencias estatales en la comercialización de la producción artesanal. En ese contexto, la migración se inserta dentro de un amplio espectro de estrategias desplegadas por los hogares para sortear las precarias condiciones de vida en un escenario de creciente pobreza.

\section{PUNTOS A DISCUSIÓN: ESTRATEGIAS Y PROCESOS CONTENCIOSOS}

Las estrategias desplegadas para sortear tal escenario muestran el rebasamiento de las mediaciones que se tejieron a través de la contención de la fuerza de trabajo bajo el modelo de sustitución de importaciones y la mutación en dichas mediaciones a partir de su transnacionalización, ahora bajo el cobijo neoliberal, lo que genera nuevas interpelaciones y procesos contenciosos, mencionados desde otros ángulos en el libro. Aquí me gustaría destacar tres:

a) El caso de la conformación de una cultura que ve en la migración una ruta legítima para alcanzar movilidad social por parte de la población joven del municipio, proceso que ocupó durante décadas el sistema educativo. En el capítulo 3, Rivermar Pérez resalta la desvinculación de la escuela en la generación de instrucciones útiles y 
flexibilizadas para las

exigencias laborales

contemporáneas. Además de la

cultura de la migración como

horizonte de movilidad,

la educación en el municipio,

como en otras partes

del contexto rural mexicano,

puede apreciarse como una

segmentación en estratos que

busca contener territorial y

subalternamente a la población

excedente. Sería interesante

conocer ante estos eventos

las nuevas formas de

constitución de los procesos

hegemónicos por fuera de la

intervención escolar.

b) La estrategia de reconversión de las políticas públicas para contener la migración
Estado genera, al no garantizar condiciones propicias para anidar oportunidades de bienestar estables en amplios segmentos de la población. Nos remite a la vez al carácter superfluo de la fuerza de trabajo y al manejo de la desechabilidad como gestión de gobierno.

c) La reproducción de distancias sociales de los grupos de migrantes en los espacios transnacionales. Ejemplo de ello es la reproducción de acendrados prejuicios étnicos y de género entre migrantes mestizos y otomíes en la ciudad estadounidense de Durham, lo que imposibilita su organización en un plano más activo políticamente y los mantiene en comunidades escindidas. Con esa forma de experimentar la clase en las comunidades de migrantes se reproduce la hegemonía neoliberal. Como señalara Gramsci (1999) respecto de las clases subalternas, la hegemonía se hace presente en la disgregación episódica y fragmentada en la que éstas experimentan su vida. Para concluir podría decir que Migraciones en la huasteca poblana. Actores y procesos es un libro útil para entender la formación de nuevos circuitos y las subjetividades que acompañan dicho movimiento. Las etnografías que contiene dicho volumen son un aporte importante para pensar otros ámbitos en México, como la morfología estatal, las políticas públicas en el proceso hegemónico, los mercados de trabajo global y la vida en los márgenes.

\section{BIBLIOGRAFÍA}

Gramsci, Antonio, 1999, Cuadernos de la cárcel, vol. 6, Benemérita Universidad Autónoma de Puebla, México. artesanales habla de la mediación líquida que el 